\title{
ESTUDO SOBRE A NUCLEAÇÃO E CRESCIMENTO DE NÓDULOS DE GRAFITA EM FERROS FUNDIDOS NODULARES*
}

\author{
André de Albuquerque Vicente ${ }^{1}$ \\ Fernando José Vilela ${ }^{2}$ \\ Victor Bridi Telles ${ }^{3}$ \\ Susana Marraccini Giampietri Lebrão ${ }^{4}$ \\ Denise Crocce Romano Espinosa ${ }^{5}$ \\ Jorge Alberto Soares Tenório ${ }^{6}$
}

\section{Resumo}

Foram estudadas três corridas comerciais de ferro fundido nodular. Para produção das corridas, partiu-se do mesmo metal base e utilizou-se a mesma liga nodularizante. Cada uma das corridas foi feita com inoculantes diferentes. Os percentuais em peso de inoculante e liga nodularizante foram, respectivamente, 1,0\% e 1,3\%. Estudou-se a nucleação e o crescimento dos nódulos de grafita. Várias técnicas complementares de análise microestrutural foram utilizadas, tais como microscopia óptica, microscopia eletrônica de varredura (MEV) e espectroscopia de raios-X por dispersão de energia (EDS). Observou-se a sequência de crescimento dos nódulos de grafita, evidenciando-se a formação de silicatos complexos ricos em alumínio, cálcio e bário ao redor dos núcleos, gerando uma interface favorável à solidificação heterogênea de grafita a partir destas partículas de tamanho superior ao raio crítico.

Palavras-chave: Ferro fundido nodular; Solidificação heterogênea; Nucleação.

\section{STUDY ON NUCLEATION AND GROWTH OF NODULAR GRAPHITE PARTICLES IN DUCTILE CAST IRON}

\section{Abstract}

Three commercial ductile cast iron heats were studied. The same base metal and nodularization alloy, were used. Each of the heats was made with different inoculants. The weight percentage of inoculant and nodularization alloy were respectively $1.0 \%$ and $1.3 \%$. The nucleation and growth of the nodular graphite particles, were studied. Several complementary techniques for microstructural analysis were used, such as optical microscopy, scanning electron microscopy (SEM) and energy-dispersive X-ray spectroscopy (EDS). It was observed the growth sequence of spheroid nodular graphite particles, demonstrating the formation of complex silicates rich in aluminium, calcium and barium around the core, creating a supportive interface to the heterogeneous solidification of graphite from these particles larger than the critical radius.

Keywords: Ductile cast iron; Heterogeneous solidification; Nucleation.

\footnotetext{
Doutorando do Departamento de Engenharia Química da EPUSP.

Doutorando em Química Tecnológica da Universidade de Brasília (UNB).

Pós-Doutorando do Departamento de Engenharia Química da EPUSP.

Professora Titular do Departamento de Engenharia Mecânica do Instituto de Engenharia Mauá.

Professora Associada do Departamento de Engenharia Química da EPUSP.

Professor Titular do Departamento de Engenharia Química da EPUSP.
} 


\section{INTRODUÇÃO}

\subsection{Produção Industrial do Ferro Fundido Nodular}

A principal diferença entre os processos de produção do ferro fundido cinzento e nodular está no processo de nodularização. A matéria prima geralmente utilizada para a produção do ferro fundido nodular é o ferro gusa.

Além do ferro gusa, pode-se utilizar em um percentual geralmente menor que $10 \%$, sucata de aço carbono [1]. Estas matérias primas são fundidas, na maioria das fundições do Brasil, em fornos à indução. Estes são fornos elétricos, compostos de uma bobina de indução que transfere calor para o material em seu interior através do efeito Joule. $O$ consumo médio de energia elétrica para fundir 1 tonelada de ferro fundido é em torno de $550 \mathrm{kWh}$ [2]. Durante a fusão são feitas as correções necessárias para ajuste da composição química, visando-se a composição final após a adição da liga nodularizante e do inoculante. O acerto da composição química geralmente é necessário para o elemento silício. Esta adição pode ser feita utilizando FeSi $75 \%$, ou silício metálico, sendo o primeiro o de menor custo.

Segundo Olsen e Hartung [3,4] e Skaland [3, 5-19], durante a fusão, o ferro fundido não deve ser aquecido a temperaturas superiores a $1550^{\circ} \mathrm{C}$, já que este superaquecimento provoca a destruição dos sítios de grafita em solução, podendo eventualmente, resultar na diminuição do número de nódulos final.

\subsection{Processo de Nodularização}

O processo de nodularização consiste no processo de obtenção do ferro fundido com grafita na forma esferoidal, ou nodular. Este processo de nodularização é conseguido graças ao efeito nodularizante de alguns elementos como magnésio, cálcio, cério e outros do grupo das terras raras. O elemento nodularizante mais utilizado é o magnésio e este é geralmente utilizado na forma de ligas com outros componentes, tipicamente ligas FeSiMg, onde os demais elementos têm a função de minimizar as reações violentas entre o magnésio e o ferro fundido base, assim como estes elementos atuam no sentido de minimizar a influência dos elementos deletérios na morfologia da grafita e controlar a composição da matriz [7, 14, 16].

Nas ligas FeSiMg, o teor de magnésio varia de 3 a 12\% em massa, e as quantidades necessárias de ligas nodularizantes variam conforme o tipo de processo utilizado e o tipo de liga adicionada, sendo que estas quantidades variam de 0,9 a $2,5 \%$.

$A$ adição das quantidades adequadas dos compostos nodularizantes é de extrema importância, já que teores excessivos de magnésio e cério, por exemplo, podem resultar na formação de carbonetos e grafita explodida ou degenerada. Os teores residuais desejados são de 0,04 a $0,08 \%$ para o magnésio, enquanto que para o cério estes teores não podem ultrapassar 0,002\% [20].

Existem várias teorias para explicar o mecanismo de nucleação e crescimento da grafita em ferros fundidos, como a teoria da bolha de gás, teoria da grafita, teoria do carboneto de silício e finalmente a teoria dos sulfetos que foi melhor compreendida com as publicações de Skaland [3, 5-19]. Este autor propõe que o magnésio adicionado através da liga FeSiMg reage com o enxofre presente no banho e forma sulfetos estáveis que resultam em pequenas inclusões finamente dispersas pelo banho. Estas inclusões servirão de base para receber uma camada de silicatos e finalmente servir de sítios para crescimento da grafita $[8,15]$. 
A fase $\mathrm{Mg}_{2} \mathrm{Si}$ é reativa no metal líquido, porém esta reatividade é menor quando comparada à reatividade do magnésio metálico. A presença de cálcio na liga nodularizante aumenta a fração volumétrica desta fase e conseqüentemente pode aumentar a recuperação do magnésio [9].

A concentração de aproximadamente $45 \%$ de silício nas ligas FeSiMg visa, justamente, a formação de silicatos complexos e diminui a violência das reações [911].

No ferro fundido nodular, durante o processo de nodularização, forma-se grande quantidade de núcleos para a precipitação da grafita. Estes núcleos são, basicamente, sulfetos de magnésio, cálcio ou cério que são recobertos por uma fina camada de silicato de magnésio. Estas partículas não servirão ainda de sítio de crescimento para a grafita devido ao fato da estrutura cristalina das mesmas não ser coerente à da grafita. Após a inoculação, a superfície destas partículas mudará devido à formação de camadas de outros silicatos e óxidos dos elementos inoculantes adicionados [11,14-17].

Os silicatos formados têm a mesma estrutura cristalina hexagonal da grafita servindo, portanto, como sítios efetivos de nucleação para o crescimento dos nódulos de grafita durante a solidificação.

Os inoculantes mais comuns são baseados em ligas de ferro silício $75 \%$ contendo pequenas e definidas quantidades dos elementos químicos cálcio, bário, estrôncio, zircônio, terras raras e alumínio. Hoje é possível encontrar inoculantes com composições químicas variadas, porém a maioria é baseada no FeSi75\%. Alguns inoculantes podem ser utilizados para inoculação em ferros fundidos cinzentos e nodulares. Isto ocorre devido ao fato dos elementos químicos cálcio, bário, estrôncio e zircônio serem fortes formadores de óxidos, sulfetos e silicatos em ambos os ferros fundidos.

A efetividade dos elementos da família II-A da tabela periódica está correlacionada à estabilidade dos óxidos e sulfetos formados e à baixa divergência do reticulado cristalino destes compostos, que servirão como substrato para precipitação da grafita $[6,8,11,13]$.

Os elementos ativos no inoculante, cálcio, bário, estrôncio e alumínio, primariamente formam óxidos e sulfetos estáveis. Estas partículas de sulfetos servirão como núcleos para o crescimento da grafita durante a solidificação [14-17].

O presente trabalho tem como objetivos o estudo da nucleação e crescimento de nódulos de grafita em ferro fundido nodular, bem como a caracterização metalográfica dos mesmos.

Deve-se mencionar que as corridas pesquisadas no presente trabalho são ferros fundidos nodulares de matriz ferrítica conforme norma ASTM A536 [25], produzidas a partir do mesmo metal base e liga nodularizante, entretanto com diferentes inoculantes.

\section{MATERIAIS E MÉTODOS}

O metal base foi fundido em um forno de indução com potência de 1000 kVA da marca Indutec com capacidade para 6 toneladas de ferro fundido líquido, utilizando-se sucata de aço carbono e ferro gusa como matéria prima.

O teor de enxofre do metal base foi corrigido para 0,015\% através de adição de pirita ao metal base inicial que apresentava teor de enxofre $0,008 \%$, melhorando-se a eficiência do processo de inoculação prevista pela teoria dos sulfetos publicada por Skaland [3,5-19]. 
O processo de nodularização foi realizado utilizando-se panela do tipo sanduíche e foi realizada a inoculação e a pós-inoculação em panelas de 600 kg e 300 kg, respectivamente.

É importante esclarecer que todas as corridas partiram do mesmo metal base utilizando-se a mesma liga nodularizante.

Cada uma das corridas foi feita com inoculantes diferentes, sendo a corrida $1 \mathrm{com} o$ FeSi $75 \%$, a corrida 2 com o FeSiBa e a corrida 3 com o FeSiMg

Os percentuais em peso de inoculante e liga nodularizante foram, respectivamente, $1,0 \%$ e $1,3 \%$.

A moldagem foi feita em areia verde. Todas as corridas foram desmoldadas 80 minutos após o vazamento.

As análises químicas foram realizadas em espectrômetro de emissão óptica, marca Spectro, através da queima de pastilhas coquilhadas. As análises específicas de carbono e enxofre foram realizadas através de pinos coquilhados pelo processo de combustão direta por infravermelho, aparelho marca Quimitron.

Realizaram-se ensaios mecânicos de tração em todos os corpos de prova em máquina universal de ensaios marca EMIC, modelo DL1000, capacidade de $100 \mathrm{kN}$. Os ensaios de tração foram realizados com carregamento constante de $10 \mathrm{MPa} / \mathrm{s}$. Em todos os ensaios utilizou-se extensômetro eletrônico marca Emic, modelo EEMA 25.

Os valores de dureza Brinell dos corpos de prova foram obtidos utilizando-se durômetro portátil, marca Microtest Brinella, penetrador de esfera com $10 \mathrm{~mm}$ de diâmetro e carga de 3000kgf.

$\mathrm{Na}$ preparação metalográfica, empregou-se o polimento manual convencional utilizando-se lixas d'água (180, 220, 320, 400 e 600 mesh) e pasta de diamante (6um e $1 \mu \mathrm{m})$. Para revelação das microestruturas escolheu-se o reagente Nital $2 \%$, que revelou de forma satisfatória a microestrutura.

A contagem de nódulos e análise de microestrutura foi realizada baseada em fotomicrografia conforme ASTM A 247 A [26].

A caracterização dos nódulos foi realizada através de microscopia eletrônica de varredura com auxílio de EDS.

\section{RESULTADOS E DISCUSSÃO}

As composições químicas do metal base, da liga nodularizante, dos inoculantes e das corridas são apresentadas na Tabela 1.

As propriedades mecânicas e as respectivas contagens de nódulos por $\mathrm{mm}^{2}$ das corridas estudadas são apresentadas na Tabela 2.

Tabela 1 - Composições químicas do metal base inicial e final (com correção do teor de enxofre), da liga nodularizante, dos inoculantes e das corridas

\begin{tabular}{l|l|l|l|l|l|l|l|l|l|l|l|l|l|l}
\hline & $\% C$ & $\% S i$ & $\% M n$ & $\% S$ & $\% P$ & $\% C r$ & $\% C u$ & $\% M g$ & $\% A l$ & $\% C a$ & $\% B a$ & $\% T R$ \\
\hline \multicolumn{10}{c}{ Metal Base Inicial e Final (com correção do teor de enxofre) } \\
\hline $\begin{array}{c}\text { Metal base } \\
\text { inicial }\end{array}$ & 3,80 & 1,61 & 0,20 & 0,008 & 0,043 & 0,02 & 0,09 & 0,00 & 0,06 & 0,00 & 0,00 & 0,00 \\
\hline $\begin{array}{c}\text { Metal base } \\
\text { final }\end{array}$ & 3,80 & 1,61 & 0,20 & 0,015 & 0,043 & 0,02 & 0,09 & 0,00 & 0,06 & 0,00 & 0,00 & 0,00 \\
\hline \multicolumn{10}{|c|}{ Liga Nodularizante } \\
\hline Mg 5 & 0,54 & 45,02 & 0,10 & 0,003 & 0,052 & 0,00 & 0,00 & 6,04 & 0,6 & 1,22 & 0,00 & 1,10 \\
\hline
\end{tabular}




\begin{tabular}{l|l|l|l|l|l|l|l|l|l|l|l|l}
\hline \multicolumn{10}{c}{ Corridas } \\
\hline Corrida 1 & 3,75 & $\mathbf{3 , 0 1}$ & $\mathbf{0 , 2 3}$ & $\mathbf{0 , 0 1 2}$ & $\mathbf{0 , 0 4 1}$ & $\mathbf{0 , 0 2}$ & $\mathbf{0 , 0 9}$ & $\mathbf{0 , 0 5}$ & $\mathbf{0 , 0 6}$ & $\mathbf{0 , 0 0}$ & $\mathbf{0 , 0 0}$ & $\mathbf{0 , 0 0}$ \\
\hline Corrida 2 & $\mathbf{3 , 7 4}$ & $\mathbf{3 , 0 6}$ & $\mathbf{0 , 2 2}$ & $\mathbf{0 , 0 1 0}$ & $\mathbf{0 , 0 4 1}$ & $\mathbf{0 , 0 2}$ & $\mathbf{0 , 0 9}$ & $\mathbf{0 , 0 5}$ & $\mathbf{0 , 0 5}$ & $\mathbf{0 , 0 2}$ & $\mathbf{0 , 0 2}$ & $\mathbf{0 , 0 0}$ \\
\hline Corrida 3 & $\mathbf{3 , 7 4}$ & $\mathbf{3 , 0 3}$ & $\mathbf{0 , 2 3}$ & $\mathbf{0 , 1 1}$ & $\mathbf{0 , 0 4 1}$ & $\mathbf{0 , 0 2}$ & $\mathbf{0 , 0 9}$ & $\mathbf{0 , 0 5}$ & $\mathbf{0 , 0 6}$ & $\mathbf{0 , 0 2}$ & $\mathbf{0 , 0 0}$ & $\mathbf{0 , 0 0}$ \\
\hline
\end{tabular}

O cálculo do carbono equivalente (CE) pode ser realizado através da Equação 1, abaixo [1]:

$$
\mathrm{CE}=\% \mathrm{C}+\left(0,33^{*} \% \mathrm{Si}+0,33^{*} \% \mathrm{P}\right)
$$

Utilizando-se as composições químicas das ligas estudadas (apresentadas na Tabela 1) na fórmula do cálculo de carbono equivalente (CE), foram obtidos os valores do carbono equivalente para cada corrida (Equações 2, 3 e 4):

Corrida 1: $\mathrm{CE}=3,75 \%+\left(0,33 * 3,01+0,33^{*} 0,041\right)=4,77 \%$

Corrida 2: $\mathrm{CE}=3,74 \%+\left(0,33^{*} 3,06+0,33^{*} 0,041\right)=4,77 \%$

Corrida 3: $\mathrm{CE}=3,74 \%+\left(0,33^{*} 3,03+0,33^{*} 0,041\right)=4,76 \%$

Conforme planejado, as três corridas estudadas apresentaram concentrações de carbono, silício e fósforo muito próximas, resultando assim em valores de carbono equivalente praticamente iguais.

Tabela 2 - Propriedades mecânicas e as respectivas contagens de módulos por $\mathrm{mm}^{2}$ das corridas estudadas desmoldadas $\mathbf{8 0}$ minutos após vazamento

\begin{tabular}{c|c|c|c|c}
\hline & Limite de Resistência (MPa) & Alongamento (\%) & Dureza Brinell & Nódulos $/ \mathrm{mm}^{2}$ \\
\hline Corrida 1 & $516+/-10$ & $15+/-1$ & $173+/-5$ & $175+/-10$ \\
\hline Corrida 2 & $520+/-10$ & $18+/-1$ & $177+/-5$ & $200+/-10$ \\
\hline Corrida 3 & $512+/-10$ & $18+/-1$ & $175+/-5$ & $200+/-10$ \\
\hline
\end{tabular}

Para cada corrida realizou-se 3 ensaios de tração. A contagem de nódulos de grafite foi feita em 10 regiões distintas para cada corpo de prova estudado. Os valores obtidos são apresentados na tabela 2 .

A Figura 1 apresenta as microestruturas das corridas estudadas, evidenciando microestrutura ferrítica-perlítica com frações volumétricas aproximadas de $90 \%$ de ferrita e $10 \%$ de perlita na matriz. A contagem de nódulos revelou $175+/-10$ nódulos $/ \mathrm{mm}^{2}$ para a corrida 1 e $200+/-10$ nódulos $/ \mathrm{mm}^{2}$ para as corridas 2 e 3 .
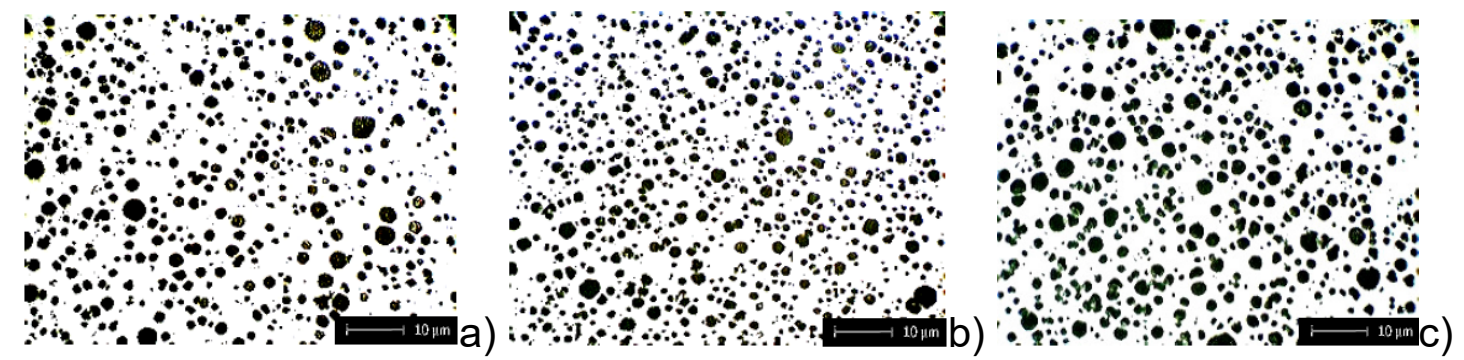

Figura 1 - Microstruturas das corridas estudadas: a) Corrida 1, b) Corrida 2 e c) Corrida 3Ferro fundido nodular de matriz ferrítica - Ataque Nital $2 \%$

A variação de temperatura entre os eutéticos estável e metaestável para uma liga binária $\mathrm{Fe}-\mathrm{C}$ é de $7^{\circ} \mathrm{C}$. Esta diferença aumenta com a adição de elementos de liga como, por exemplo, o silício. Ligas com teor de Si próximo a $2 \%$ em peso apresentam diferença de até $35^{\circ} \mathrm{C}$ entre os patamares eutéticos estável e metaestável. Elementos que aumentam a diferença entre os patamares eutéticos estável e metaestável são chamados grafitizantes, ou seja, favorecem a solidificação da grafita. Entre os principais elementos grafitizantes estão o silício, o cálcio e o bário. Já os elementos que diminuem a diferença entre os patamares eutéticos estável e metaestável são 
ditos perlitizantes, ou seja, favorecem a formação de cementita ( $\left.\mathrm{Fe}_{3} \mathrm{C}\right)$. Entre estes elementos estão o manganês, o níquel, o cobre, o estanho e o cromo. Para concentrações de cromo acima de $2 \%$ ocorre o cruzamento dos patamares eutéticos estável e metaestável, podendo-se considerar nestas condições que a solidificação ocorre somente segundo o diagrama metaestável, ou seja, forma-se cementita eutética [21].

O processo de solidificação de um metal líquido ocorre, com a diminuição da temperatura, em duas etapas sequenciais, sendo elas a nucleação e o crescimento dos cristais.

Na solidificação de uma liga hipereutética, a primeira fase a se solidificar é a grafita, com a formação do núcleo de grafita diretamente no metal líquido. O líquido vai se empobrecendo de carbono até que na temperatura eutética ocorre a solidificação da fase líquida ainda presente formando a ledeburita. Os nódulos de grafita que foram formados previamente no líquido são envolvidos por uma camada de austenita. $\mathrm{Na}$ seqüência ocorre a diminuição do teor de carbono da austenita, através da difusão do carbono desta para os nódulos de grafita. Na temperatura eutetóide ocorre a transformação da austenita em cementita e perlita [22].

Estudos de Turnbull e Vonnegut [23] demonstraram que na nucleação heterogênea de um ferro fundido, o super-resfriamento necessário para formação dos primeiros núcleos é de 2 a $10^{\circ} \mathrm{C}$, quando se utiliza inoculantes. Ainda segundo este autor, este baixo super-resfriamento está relacionado com as divergências do reticulado cristalino entre os compostos formados a partir do inoculante e a grafita, que estaria entre 3 a $10 \%[23,24]$.

O baixo super-resfriamento observado na solidificação do ferro fundido nodular também é mais uma evidência que, ao menos uma quantidade mínima de nucleação heterogênea ocorre, já que, para ocorrer somente a nucleação homogênea da grafita o super-resfriamento necessário seria maior que $250{ }^{\circ} \mathrm{C}$, promovendo solidificação metaestável e promovendo a formação de carbonetos [23, 24].

A Figura 2 apresenta a caracterização microestrutural de um dos nódulos de grafita da corrida 1, dissecado, revelando um núcleo rico em silício, alumínio e cálcio, recoberto por grafita.

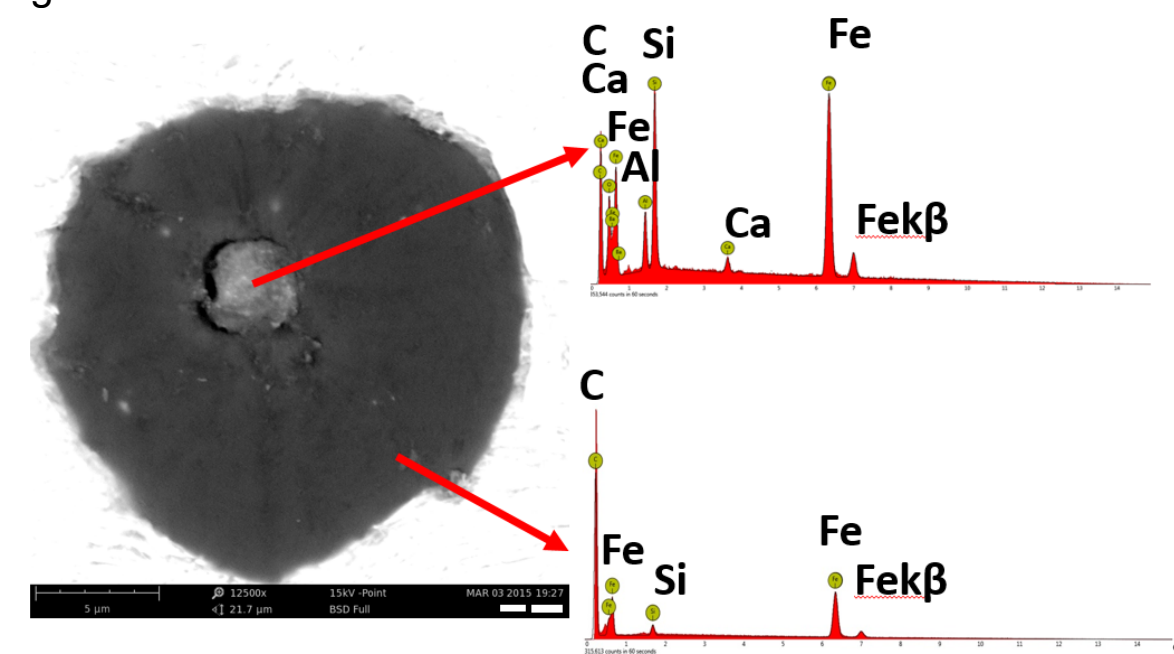

Figura 2 - Nódulo de grafita da corrida 1 inoculada com FeSi75\%, revelando um núcleo rico em $\mathrm{Si}, \mathrm{Al}$ e $\mathrm{Ca}$ recoberto por uma camada externa de grafita

A Figura 3 apresenta a caracterização microestrutural de um dos nódulos de grafita da corrida 2 dissecado revelando formação de uma camada rica em silício, alumínio, cálcio e bário, recoberta por grafita. 

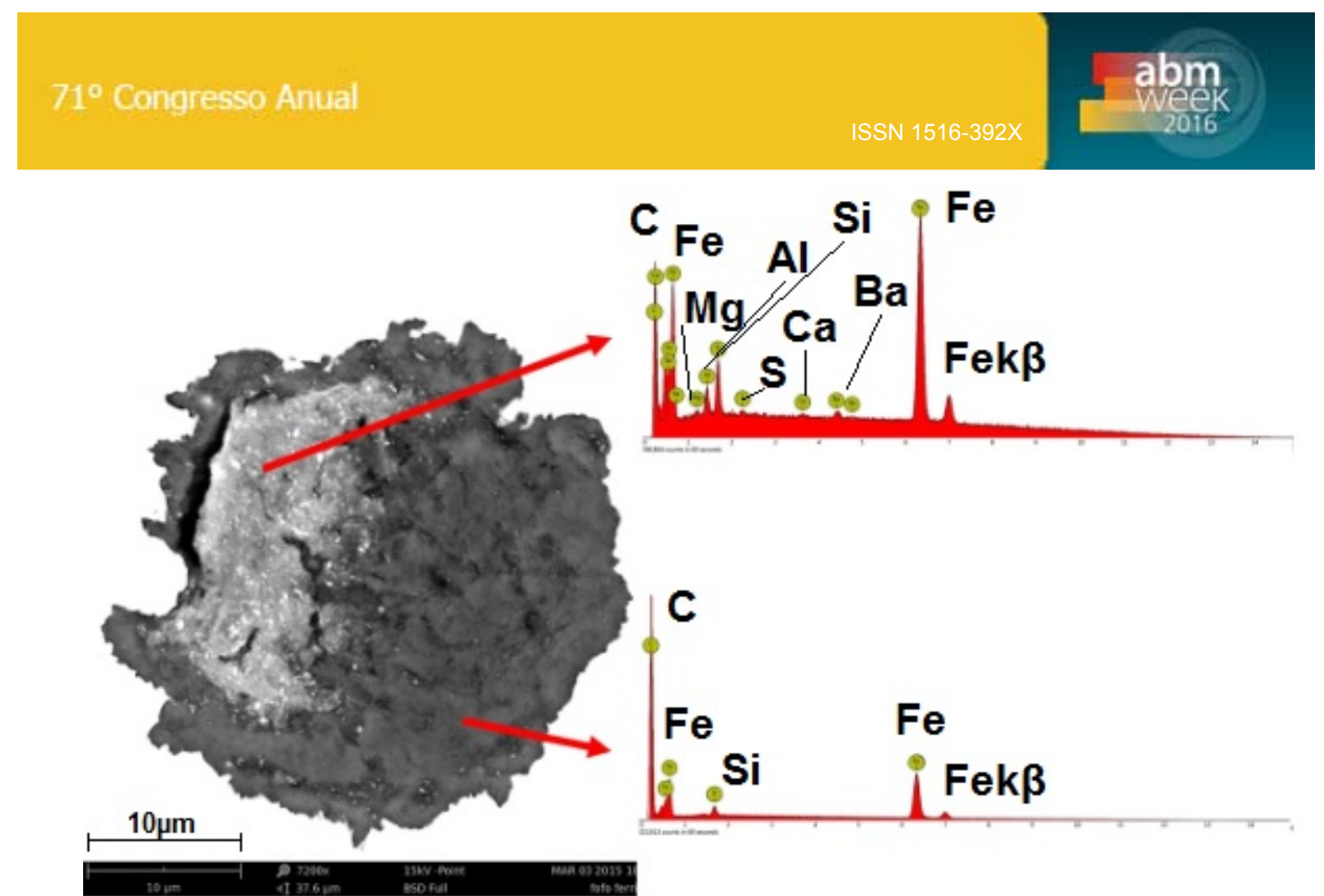

Figura 3 - Nódulo de grafita da corrida 2 inoculada com FeSiCaBa, revelando um núcleo rico em $\mathrm{Al}, \mathrm{Ba}, \mathrm{Ca}, \mathrm{Mg}$ e $\mathrm{S}$ recoberto por uma camada externa de grafita

A Figura 4 apresenta a caracterização microestrutural de um dos nódulos de grafita da corrida 3 dissecado revelando um núcleo rico em silício, cálcio, oxigênio e enxofre, recoberto por grafita.

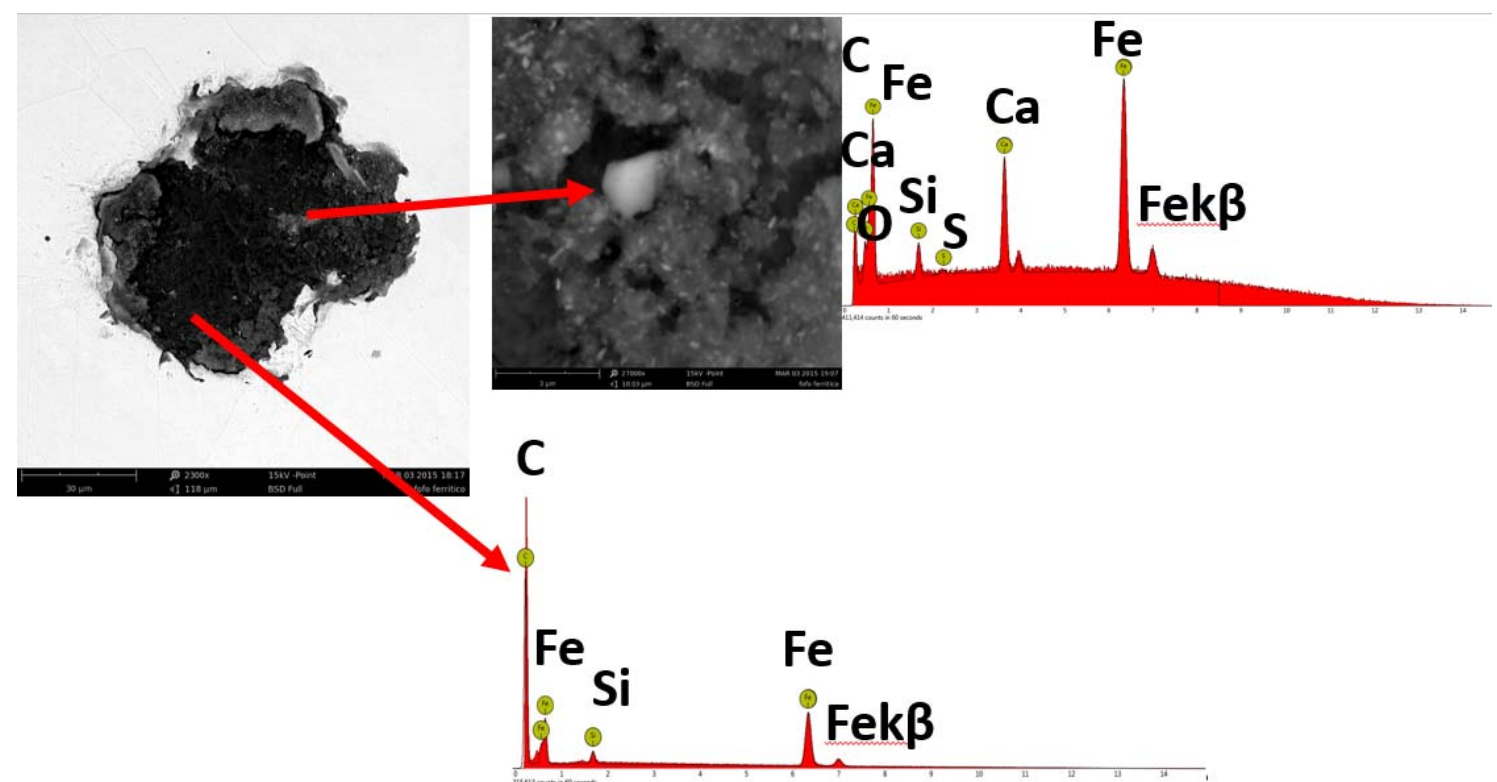

Figura 4 - Nódulo de grafita da corrida 3 inoculada com FeSiMg, revelando um núcleo rico em $\mathrm{Si}, \mathrm{Ca}, \mathrm{O}$ e $\mathrm{S}$ recoberto por uma camada externa de grafita.

Na sequência teórica de solidificação de uma liga $\mathrm{FeC}$ hipereutética, o primeiro sólido a formar-se é a grafita. Desta forma, se existir uma grande quantidade de partículas com alto ponto de fusão, finamente dispersas no banho, e com raio maior que o raio crítico, a precipitação de nódulos de grafita é termodinamicamente viável.

Durante o processo de nodularização, forma-se grande quantidade de núcleos para a precipitação da grafita. Estes núcleos são, basicamente, sulfetos de magnésio, 
cálcio ou cério que são recobertos por uma fina camada de silicato de magnésio. Estas partículas não servirão ainda de sítio de crescimento para a grafita devido ao fato da estrutura cristalina das mesmas não ser coerente à da grafita. Após a inoculação, a superfície destas partículas mudará devido à formação de camadas de outros silicatos e óxidos dos elementos inoculantes adicionados.

Os silicatos formados têm a mesma estrutura cristalina hexagonal da grafita servindo, portanto, como sítios efetivos de nucleação para o crescimento dos nódulos de grafita durante a solidificação.

\section{CONCLUSÃO}

As propriedades mecânicas obtidas para as três corridas estudadas, evidenciam claramente a relação direta entre o alongamento e a quantidade de nódulos $/ \mathrm{mm}^{2}$.

A corrida 1, inoculada com FeSi75\% apresentou a menor quantidade de nódulos $/ \mathrm{mm}^{2}$ e, consequentemente, menor alongamento.

A caracterização metalográfica dos nódulos de grafita através de microscopia eletrônica de varredura (MEV) com EDS acoplado, sugere que a grafite cresça a partir de silicatos complexos ricos em $\mathrm{Al}$, $\mathrm{Ca}$ e $\mathrm{Ba}$ de tamanho superior ao raio crítico.

\section{REFERÊNCIAS}

1 Karsay, S I. Ductile Iron - Productin and Pratice. American Foundry Society, USA, 1985

2 Edneral, F.P. Electrometallurgical of Steel and ferro Alloys. Volume 2. Mir Publishers. Moscow, 1979

3 Olsen, S.O; Skaland, T., Hartung, C. Inoculation of grey and ductile iron: A comparison of nucleation sites and some practical advises. World Foundry Congress, Turkey, 2004.

4 Olsen S.O.; Hartung, C; Recovery of Magnesium in a Ductile Iron Process. Elkem Technical Information Sheets, Elkem Foundry Products, Kristiansand, Norway, 2001

5 Skaland, T. A new method for chill and shrinkage control in ladle treated ductile iron. World Foundry Congress, Turkey, 2004.

6 Skaland, T., A Model for the Graphite Formation in Ductile Cast Iron, Ph.D. Thesis 1992:33, The University of Trondheim, NTH, Department of Metallurgy, Norway, 1992

7 Skaland, T. A New Method for Chill and Shrinkage Control in Ladle Treated Ductile Iron Keith Millis Symposium on Ductile Iron, Las Vegas, EUA. 2003.

8 Skaland, T.; Nucleation Mechanisms in Ductile Iron, Proceeding of the AFS Cast Iron Inoculation Conference, Schaumburg, Illinois, September, 2005

9 Skaland, T.; Ductile Iron Production - A Comparison of Alternative Treatment Methods, Metal Casting and Surface Finishing, Elkem Technical Information Sheets, Elkem Foundry Products, Kristiansand, Norway, 1999

10 Skaland, T.; Ductile Iron Shrinkage Control Through Graphite Nucleation and Growth. Elkem Technical Information Sheets, Elkem Foundry Products, Kristiansand, Norway, 2002

11 Skaland, T.; A New Approach to Ductile Iron Inoculation, AFS Transation, EUA, 2001

12 Skaland, T.; A New Method for Chill and Shrinkage Control in Ladle Treated Ductile Iron, Elkem Technical Information Sheets, Elkem Foundry Products, Kristiansand, Norway, 1999

13 Skaland, T.; Developments in Cast Iron Metallurgical Treatments. Elkem Technical Information Sheets, Elkem Foundry Products, Kristiansand, Norway, 2001

14 Onsoien, M.I.; Grong, O., Gurdersen, O.; Skaland, T; A Process Model for Microstructure Evolution in Ductile Cast Iron - Part I - The Model. Metallurgical and Materials Transactions A, Vol. 30A, April, 1999a 
15 Onsoien, M.I.; Grong, O., Gurdersen, O.; Skaland, T; A Process Model for Microstructure Evolution in Ductile Cast Iron - Part II - Applications of the Model - The Model.

Metallurgical and Materials Transactions A, Vol. 30A, April, 1999b

16 Onsoien, M.I.; Grong, O., Skaland, T; Jorgensen, K.; Mechanisms of Graphite Formation in Ductile Cast Iron Containing Rare Earth Metals, Materials Science and Technology, vol. 15, Mach 1999

17 Onsoien, M.I.; Grong, O.; Rorvik, G.; Nordmark, A.; Skaland, T.; Design and Development of Treatment Alloys for Ductile Cast Iron, International Journal Cast Metals Research, Vol. 10, 1997

18 Skjegstad N.T.; Skaland, T.; Inoculation of Grey and Ductile Iron. Bombay Foundry Congress, Indian, 24 -25 May, 1996

19 Skjegstad, N.T.; Skaland, T.; Inoculation of Grey and Ductile Iron - A comparison of Nucleation Sites and Some Practical Advises, Bombay Foundry Congress, Indian, 24 -25 May, 1996

20 Ecob, C.M.; Review of Common Metallurgical Defects in Ductile Cast Iron. Elkem Technical Information Sheets, Elkem Foundry Products, Kristiansand, Norway, 1998

21 Santos; A., B.,S.; Castello. Branco, C. H. Metalurgia dos ferros fundidos cinzentos e nodulares. Instituto de Pesquisas Tecnológicas - IPT 1989

22 Chiaverini, V. Aços e Ferros Fundidos, 4 ed. Associação Brasileira de Metais. SP, 1977

23 TurnBull, D; Vonnegut, R. Industrial Engineering Chemistry, Vol 44, 1952.

24 Minkoff, I. The physical metallurgy of cast Iron, John Wiley \& Sons, NY, 1983

25 ASTM, American Society For Testing And Materials. A 536: Standards specific for ductile iron casting, 1997

26 ASTM, American Society For Testing And Materials. A 247 A: Adjunct to A247A Iron Casting Graphite Microstructure Rating Wall Chart, 2010 